Tibor Rutar

\title{
Marx postmarksizma
}

Ključne besede: postmarksizem, determinizem, kritika politične ekonomije, neoklasična ekonomija

Delovati proti dominantnim institucijam od znotraj zahteva nasprotovanje raznoterim institucionalnim formam, ki reproducirajo institucionalno moč in dominacijo vladajočega razreda nasploh, medtem ko "postati institucionaliziran« pomeni izpolnjevati potrebe institucij za nove oblike reprodukcije te dominacije (Katz, 1995/1996, 66).

$\mathrm{V}$ sedemdesetih in osemdesetih letih prejšnjega stoletja, $\mathrm{v}$ obdobju neoliberalne kontrarevolucije, ko je bila raven življenjske sile kapitalizma - živega dela, z vsrkavanjem katerega se kapital oživi kakor vampir (Marx, 1986, 214) - kritično nizka, tako da je sistem kot nor iskal še zadnje neizkoriščene sfere družbenega življenja, ki bi ga lahko navdale $\mathrm{z}$ življenjem, je v postmodernem okolju zahodne univerze vzniknila »nova» paradigma, ki je bila v svoji protoformi navzoča že pri Nietzscheju in Heideggerju (Goldner, 2011). Te nove antidialektične, netotalizirajoče vede, ki t. i. metapripovedi in razsvetljenske ideale zavračajo $\mathrm{v}$ imenu relativizma, eklekticizma in »radikalne demokracije«, se ukvarjajo s študijo politike, ideologije, diskurza in identitete (oziroma, kot bi nas verjetno hiteli popraviti, politik, ideologij, diskurzov in identitet: te so namreč kvalitativno nujno heterogene in ireduktibilne). ${ }^{1} \mathrm{~V}$ nasprotju s praksami, kakršna je sociologija kulture, privzamejo obstoječi institucionalni in ideološki okvir kapitalističnega produkcijskega načina za danega. Osrednji predmet raziskovanja ni več s teorijo vrednosti prepojena kritična analiza kulturne zavesti in ideoloških praks, ki prevladujejo v družbenem življenju, pogojenem s kapitalizmom, temveč afirmativno proučevanje pisanih diskurzov, različnih pojavnih oblik družbenega življenja, ki je subsumirano pod tržno logiko, in potencialne (ali celo neizbežne) subverzivnosti vsega in vsakogar, ki ni beli zahodni moški.

Problematizirali bomo (a) prehitro postmarksistično kritiko Marxa, ki izenačuje (vulgarni) marksizem in Marxa, ter (b) popolno ignoranco glavnega prispevka Marxove teorije vrednosti, tj. kritike postvarelih kapitalističnih produkcijskih odnosov. Problem postmarksističnih kritik marksizma je predvsem ta, da zaradi svoje (ne nujno

1 »Po Heglu in Marxu je razlika protislovje, ki nakazuje višjo sintezo; po postmodernistih pa je razlika nezvedljiva razlika, višja sinteza pa je le nov diskurz moči, nova vzvišena pripoved « (Goldner, 2011, 97). 
neupravičene) kritike marksističnih teorij ideologije hote ali nehote ignorirajo Marxov glavni teoretski prispevek - kritiko politične ekonomije - in s tem Marxa samega. Hkrati Marxovi misli pripisujejo značilnosti, ki so v najboljšem primeru znamenje njegovega neutrudnega boja zoper idealistične tendence iz prve polovice 19. stoletja, ne pa resni in razdelani koncepti ideologije.

Vsaj eksplicitno nas torej ne bo toliko zanimalo najpogostejše vprašanje o postmarksistih, tj. vprašanje veljavnosti njihove kritike marksističnih teorij ideologije. Nasprotno, problematizirali bomo predvsem obfuskacijo, ki so jo proizvedle teorije tega postmodernega teoretskega polja, in vulgarizacijo Marxove misli, ki je v istem času potekala tudi na področju marksovske ekonomije, kjer so fizikalistične neoricardovske (sraffovske) in neoklasične teorije mrcvarile teorijo vrednosti, da bi jo integrirale $\mathrm{v}$ svoje formalnoabstraktne modele splošnega ravnovesja in odvrnile pozornost od kritične implikacije teorije vrednosti, da je abstraktno človeško delo edini vir vrednosti. To vztrajno paradiranje pod nasprotnikovo - Marxovo - zastavo se je v drugi polovici prejšnjega stoletja stopnjevalo na različnih področjih »marksizma«. A ne glede na dobronamernost zastavonoš so različne nematerialne, bojda emancipatorne oblike dela ter Marxov domnevni ekonomski redukcionizem goli konstrukti, ki jih je treba demistificirati.

\section{Nova družbenopolitična veda za »novo« kapitalistično dobo}

Čeprav ti postmarksisti nominalno črpajo iz misli Karla Marxa, je ta pogosto zvedena na nekaj površnih sociologizirajočih opomb o razredni naravi kapitalistične družbe (pri čemer seveda ne pozabijo pripomniti, da naj bi Marx $\mathrm{v}$ revolucionarni ihti prezrl pluralnost družbenih akterjev, ki jih ne gre zvesti na vsega dva razreda) in na idejo Weltanschauung marksizma, po kateri lahko celotno dinamiko družbenega življenja koncipiramo prek metafore baze in nadzidave, po kateri naj bi ekonomija nerefleksivno določala vse. ${ }^{2}$ Niti besedice ne slišimo o tistih Marxovih prispevkih, ki jih je v osebni korespondenci sam navajal kot najpomembnejše - na primer o dvojnem značaju dela in o vrednostni formi. Temu se še najbolj približamo pri omembi blagovnega fetišizma, ki pa je žal običajno

2 Kot da Marx ne bi bil mislec dialektike, pri kateri gre za neskončno konsekvenco realizacij mnogoterih potencialnosti. Realizirani fenomeni vsebujejo različne potencialnosti in jih zato determinirajo (Carchedi, 2011, 3-22). A ko pride do realizacije določene potencialnosti, ta postane realizirani fenomen, ki določa nove potencialnosti. Pri Marxovi dialektiki sta osrednjega pomena temporalnost (ne statičnost) in vzajemna prepletenost (ne unikavzalna determiniranost). Le to, kar je že realizirano, lahko določa tisto, kar šele bo realizirano; to ni redukcionizem, temveč realnost družbenih fenomenov (prav tam). Razglašati, da je Marx aksiomatično zatrjeval, da ekonomija nepovratno determinira ideologijo, priča predvsem o nepoznavanju njegovih spisov, katerih namen je kritika kategorij politične ekonomije, ne razvijanje teorije ideologije. 
predstavljen bodisi kot lažna zavest (kar je prav tako vulgarnomarksistična koncepcija, ki izvira iz popularizacij »Marxove teorije « v času druge internacionale) bodisi kot špekulativna metafizika.

Kristalizacija družbenih produkcijskih odnosov, ki je motila Marxa, postmarksizma ne moti več: privzame jo za dano, saj ne problematizira liberalnokapitalističnega ustroja družbe. Zdi se, da je postmarksizem (v svoji najbolj problematični in prevladujoči inačici) podoben neoklasični ekonomiji, kolikor ga ne zmoti postvarelost in odtujenost družbenih odnosov in Marxa pokroviteljsko odslovi kot misleca preživele moderne. Izkazalo se je, da je ta slamnati mož, ki so ga že od izdaje zadnjega zvezka Kapitala samozadovoljno krpali skupaj tako Marxovi samooklicani nasledniki kakor njegovi goreči nasprotniki, integralni del pogoja postmarksizma.

Stuart Hall, ki se predstavlja kot postmarksist in poststrukturalist (Bowman, 2007, 4), in Ernesto Laclau, ki je skupaj s Chantal Mouffe utemeljeval postmarksizem, pojasnjujeta, da je postmarksizem postmarksizem, saj naj poenostavljeni odnos med razredno dominacijo in ideološkimi, kulturnimi in političnimi formami družbenih subjektivitet, ki naj bi ga ponujal marksizem, preprosto ne bi bil več prepričljiv: »Eden ključnih problemov marksizma se nanaša na redukcionizem njegove teorije determinacije. Za marksizem je determinacija bolj ali manj vsega navezana na nekaj 'esencialnega' glede razredov in gospodarstva, pojmovanih kot zaprt sistem " (Bowman, 2007 , 4). Obenem naj bi bil postmarksizem postmarksizem, saj naj bi se v temeljih še vedno opiral na marksizem (prav tam).

$\mathrm{Ni}$ naključje, da je Marxovo življenjsko delo naslovljeno Kapital in podnaslovljeno Kritika politične ekonomije. Kapital je imanentna kritika kategorij politične ekonomije. Teorija ideologije sploh ni bila Marxov načrt, zato je izločitev peščice izjav o ideologiji iz izjemno obsežne in dosledne kritike političnih ekonomistov $\mathrm{v}$ najboljšem primeru naivna, $\mathrm{v}$ najslabšem pa načrtno zlonamerna. Očitati Marxu, da ni podal prepričljive teorije ideologije, je tako čudaško kakor nepošteno. Antonio Gramsci, Louis Althusser in podobni marksisti, ki so izhajali iz teorije vrednosti in so razvijali marksistično teorijo ideologije, so se v nasprotju $\mathrm{z}$ Marxom tudi predstavljali kot teoretiki ideologije, a niso Marx in njihovo teoretsko delo nima nujnih implikacij za veljavnost teorije vrednosti kot kritike politične ekonomije in kot podlage za emancipatorni boj par excellence, tj. boj proti tiraniji abstrakcij. Postmarksistična kritika postmarksovskega marksizma, tj. deklarativno marksistične teorije, ki je nastajala po Marxovi smrti, je torej lahko povsem ploden projekt, toda: (a) nobena tovrstna kritika marksizma ni avtomatično pertinentna za Marxovo teorijo, saj se ukvarja $\mathrm{z}$ njenimi modifikacijami ali nadgradnjami, ne z njo samo; (b) čeprav se izkaže, da so se Gramsci, Althusser in podobni marksisti motili, 
to še ne ovrže teorije vrednosti, saj se ta ne ukvarja s kulturo ali ideologijo, temveč s kritiko politične ekonomije.

Postmarksizem in kulturni študiji, ki jih družita kritika in hkrati sprejemanje Marxa, ne problematizirajo postvarelosti družbenih produkcijskih odnosov in posplošene blagovne menjave, saj zanje to nista področji (oziroma privilegirani področji) emancipatornega boja. Tako postane irelevantna Marxova identifikacija blagovnega fetišizma - tj. inverzije kavzalne relacije objekt-subjekt, do katere pride v kapitalističnem produkcijskem načinu - kot temeljnega elementa odtujenosti in nečloveškosti življenja v kapitalizmu. A vendar si je težko predstavljati kaj bolj emancipatornega kakor razbitje dominacije stvari nad ljudmi, neosebne prisile, ki vlada tako lastnikom produkcijskih sredstev kakor vsem ostalim. To seveda ne pomeni, da boji proti vsakršni diskriminaciji ter za politično, kulturno, etnično in spolno emancipacijo niso »pravi boji«. Pa vendar te vrste upora zoper vladavino ljudi nad ljudmi ne problematizirajo bizarnejšega fenomena, specifičnega za kapitalizem, tj. vladavine stvari nad ljudmi. Od tod jasna razlika med tema vrstama emancipacije: prva je dosegljiva $\mathrm{v}$ obstoječi družbeni formaciji, druga pač ne. Adam Katz tako pravi:

$\mathrm{V}$ nasprotju s trditvami Baudrillarda, Laclaua in Mouffove kategorija dela v marksizmu ne projicira »identitete«, temveč opisuje podlago za kapitalistični družbeni red in s tem razlaga, glede česa in zakaj se subjekti - ne glede na to, kako se »identificirajo« - bojujejo (Katz, 1995/1996, 67).

Marx v Kapitalu analizira historično specifično družbeno tvorbo, ki jo zaznamujejo poteze, kakršna je boj proti obstoječim materialnim odnosom med ljudmi in družbenim odnosom med stvarmi. Identitetne politike, na katere se sklicuje postmarksizem, pa niso specifične za kapitalistični produkcijski način, četudi so izjemno pomembne za človeško emancipacijo. Ti vrsti boja sta torej nekomenzurabilni, saj je le prva antikapitalistična. ${ }^{3} \mathrm{Tu}$ je srž problema ter vir všečnosti postmarksizma in kulturnih študijev za akademski milje sodobne buržoazne formacije: postmarksizem in kulturni študiji so implicitno apologetski, čeprav so videti radikalni.

\section{Pogojuje ali določa ( $v$ zadnji instanci)?}

Predgovor k Prispevku h kritiki politične ekonomije je eden glavnih virov obtožb, da je bil Marx ekonomski determinist. Tam naj bi Marx zapisal, da konflikt med produktivnimi silami in produkcijskimi odnosi določa politiko, ideologijo, kulturo in človeško zavest nasploh. Toda obtožbe izpuščajo vsaj dvoje.

3 Za podrobnejšo argumentacijo glej Carchedi (2011, 14-15). 
Prvič, slovenski prevod, ki pravi, da "način produkcije določa socialni, politični in duhovni proces življenja« (Marx, 1979b, 105), je kakor mnogi drugi prevodi zavajajoč. Izvirnik namreč pravi: »Die Produktionsweise des materiellen Lebens bedingt [pogojuje] den sozialen, politischen und geistigen Lebensprozeß überhaupt « (Marx, 1971, 8-9). Poudarek, da po Marxu ekonomija določa vse drugo (vsaj v zadnji instanci), je torej napačen, če že ne zlonameren.

Drugič, ko pa Marx res piše o določitvi (bestimmen) - »družbena bit določa zavest « (Marx, 1979b, 105) -, se predvsem odziva na leve heglovce, ki zatrjujejo, da zavest določa bit. Prav ta kritični element pa je običajno izpuščen. Čeprav gre torej predvsem za agitacijsko parolo, se Marx ne zadovolji z diametralno inverzijo teze, ki bi zvenela deterministično (Stillman, 2005), in bit specificira kot družbeno bit. Domnevno sporni odlomek iz predgovora bi namreč moral biti preveden takole:

Način produkcije materialnega življenja [pogojuje] socialni, politični in duhovni proces življenja nasploh. Ne določa zavest ljudi njihove biti, temveč narobe, njihova družbena bit določa njihovo zavest (Marx, 1979b, 105).

Najbrž ni resnega družboslovnega znanstvenika, ki se ne bi strinjal s to Marxovo skoraj vsakdanjo ugotovitvijo, da smo ljudje od rojstva vpeti v družbeni kontekst, ki si ga ne izbiramo sami (čeprav ga lahko tudi spreminjamo): pred formacijo naše zavesti je že vzpostavljen okvir, ki vpliva na to formacijo, četudi ga kasneje spremenimo. Kot na drugem mestu pravi Marx:

Ljudje delajo svojo lastno zgodovino, toda ne delajo je, kakor bi se njim zljubilo, ne delajo je v okoliščinah, ki so si jih sami izbrali, temveč v okoliščinah, na kakršne so neposredno zadeli, kakršne so bile dane in ustvarjene s tradicijo. Tradicija vseh mrtvih pokolenj leži kakor mora na možganih živih ljudi (Marx, 1979a, 452).

Kot rečeno, bolj kakor postmarksistične kritike neomarksističnih teorij ideologije želimo tu demistificirati determinizem in redukcionizem, ki ju te kritike implicitno ali eksplicitno pripisujejo Marxovi kritiki politične ekonomije, tj. predvsem teoriji vrednosti.

\section{Politična ekonomija postmarksizma}

Predstavljeni sta nam dve strani: na eni imamo rigidni, esencialistični, deterministični, monistični, teleološki, statični, redukcionistični, ekonomistični in zgolj materialistični marksizem (ki naj bi bil povsem homogeno ideološko polje), na drugi pa prilagodljivi, nedoločeni, pluralistični, odprti, dinamični in heterogeni postmarksizem. ${ }^{4}$ Ta prehod od domnevno anahronega marksizma $\mathrm{v}$

4 Nazoren primer te lažne dihotomije je knjiga Class and Civil Society (Cohen, 1987), ki govori o 
menda svežo teorijo ideologije je problematičen že v izhodiščih. Na primer Laclauov postmarksizem zaznamujeta vsaj dva odločilna nesporazuma, ki resno ogrožata njegovo teoretsko podlago. »Razredno protislovje« ni »dominantno protislovje obstoječega produkcijskega načina«, kakor trdi Laclau (1977, 108): izhodiščno protislovje obstoječega sistema ni med kapitalističnim razredom in delavskim razredom, temveč - kot pokaže kritika politične ekonomije, ki jo Laclau hitro odslovi - med uporabno vrednostjo (konkretnim, subjektivnim, fluidnim človeškim izkustvom) in vrednostjo (abstraktnim, objektivnim, postvarelim, neosebnim imperativom). Kot pričajo bridke izkušnje prejšnjega stoletja, človeštvo emancipacije ne more doseči s samim strmoglavljenjem vladajočega razreda (ki je zgolj konkretna, živa, inkarnirana forma abstraktnega, brezobličnega, mrtvega objekta - kapitala) ${ }^{5}$, temveč mora njeno sidrišče iskati v praksi transformiranja postvarelih kapitalističnih produkcijskih odnosov.

A to ni edino problematično mesto $\mathrm{v}$ Laclauovem postmarksističnem pristopu. Njegovo pomanjkljivo spoprijemanje z Marxovo teorijo vrednosti je na primer očitno, ko med drugim proti Žižkovemu zagovoru marksovske politične ekonomije pravi:

Kritika [marksovske politične ekonomije] je možna in - čeprav je nisem formuliral sam - je bila v zadnjem stoletju tolikokrat ponovljena, da je od delovne teorije vrednosti, kot jo je predstavil Marx, ostalo bore malo. Naj omenimo le Eugena von Böhm-Bawerka, Ladislaua Bortkiewicza, Joan Robinson ali Piera Sraffo (Laclau, 2006, 658-659).

Laclau tu nehote prizna, da teorija vrednosti, ki jo kritizira, sploh ni Marxova. Vzporednica, ki jo vlečemo med postmarksizmom in neoklasično ekonomijo oziroma neoklasično vulgarizacijo teorije vrednosti, bi bila brez tega citata brez dvoma prehitra in neprepričljiva, zgolj naključna, četudi zanimiva korelacija. A tu vidimo, da Laclau brezsramno priznava, da je njegov Marx v resnici Marx buržoaznih ekonomistov - tako najočitnejših, med katerimi sta Böhm-Bawerk ${ }^{6}$ in Bortkiewicz, kakor malce

dediferenciaciji države in družbe pri Marxu, kot da je bil Marx teoretik etatizma, ne pa njegov največji nasprotnik (Goldner, 2011, 114-115). Marx naj bi se v radikalni komunistični drži nevarno gibal med romantičnim utopizmom in tehnokratskim etatizmom - izbira terminov v luči njegove neizprosne kritike utopičnih socialistov in etatizma verjetno ne bi mogla biti bolj ponesrečena. Marx naj bi v Komunističnem manifestu in Kapitalu socializem obravnaval na podlagi tehnokratskih in etatističnih idealov - a v teh delih Marx o socializmu govori redko in predvsem popolnoma drugače: "[Z]druženje svobodnih ljudi« (Marx, 1986, 78) ter "popoln in svoboden razvoj vsakega individua« (Marx, 1986, 538). So mar to tehnokratični in etatistični ideali?

$5 \quad$ Kapitalist je le poosebljen kapital (Marx, 1986, 538).

6 Po Böhm-Bawerku je Marxovo pripoznanje vrednosti in (produkcijskih) cen, ki lahko po velikosti sovpadejo le po naključju, očitno priznanje nerešljivega protislovja med prvo knjigo Kapitala (kjer se blago prodaja po vrednostih) in tretjo knjigo Kapitala (kjer se blago prodaja po cenah). Vendar iz Kapitala jasno izhaja, da je neujemanje med velikostmi vrednosti in velikostmi cen esencialni pogoj Marxove teorije vrednosti (in kapitalističnih gospodarstev, v katerih obstajata ponudba in 
subtilnejših, kakršna je Joan Robinson. Ker naš tukajšnji namen ni vsebinska demistifikacija buržoazne vulgarizacije Marxove teorije vrednosti, ne moremo pokazati, zakaj t. i. "problem« transformacije vrednosti v produkcijske cene, ki ga s sklicevanjem na zgornje ekonomiste omenja Laclau, ni Marxov problem, ampak problem simultanistične neoklasične (neoricardovske oziroma sraffovske) ekonomije, ki v nasprotju z resničnim svetom ne priznava temporalnosti. Bralca ali bralko pa lahko vsaj napotimo na Klimanove (2007), Carchedijeve (2011), Freemanove (1996) in druge spise marksovskih ekonomistov, ki Marxa ne berejo skozi lečo buržoazne ideologije in ki notranjo konsistentnost njegove teorije ocenjujejo na podlagi njegovih in ne tujih premis (pri čemer seveda opozarjajo, da notranja konsistentnost teorije še ne dokazuje veljavnosti njenih premis). Nadaljnji razvoj teorije vrednosti in nasploh marksistične teorije preprosto ni mogoč, če se ne odrečemo temu mitu o notranji nekonsistentnosti.

Fleksibilne, dinamične in nerazredne »identitete«, o katerih govorijo postmarksisti, kot po naključju ustrezajo materialnim pogojem sodobnega kapitalizma. Kajti ta zaradi svoje trenutne betežnosti, ki jo je sprožila stagflacijska kriza sedemdesetih let, za nadaljnjo akumulacijo kapitala potrebuje fleksibilni, deradikalizirani, nespecializirani (specializacija naj bi bila totalitaren relikt moderne), postmoderno kreativni prekariat. Ta novi kognitivni delavec, ki ga nenehno rekonstituiranje njegove identitete ne moti in ki rade volje opravlja svoje delo na domu ali na dolgi poti v službo, je za akumulacijo kapitala veliko primernejši kakor zatohli tovarniški delavec, ki osem ur gara za tekočim trakom, nato pa preostanek dneva izčrpan od mehanicističnega, odtujenega dela ždi pred televizijo. S tem prehajamo na drugo problematiko postmarksističnih teorij, ki pa so kljub temu posledica že omenjene reinterpretacije Marxa, zaradi katere v teh teorijah ni veliko prostora za kritiko politične ekonomije ali pa je ta prostor zelo bedno izkoriščen.

Paradigmatski primer je Negrijevo (2008) postmarksistično slavljenje kognitivnega kapitalizma oziroma družbe znanja, v kateri omenjeni kreativni delavec pridobi nekaj svoje nekoč izgubljene avtonomije in s tem kljubuje disciplini kapitala. Pri tem ni pomembno to, da Negri zmotno stavi na nadaljevanje (in dejansko poglobitev) realne subsumpcije dela pod kapital kot na priložnost za nenadejano komunistično emancipacijo, ampak to, da svojo apologijo legitimira $z$ marksovsko zvenečo »analizo«. Po njegovem prehod v kognitivni kapitalizem pomeni krhanje

povpraševanje), ne dokaz njene protislovnosti. Že v prvi knjigi Marx $(1986,98)$ pravi: »Možnost kvantitativne inkongruence med ceno in velikostjo vrednosti ali odstopanje cene od velikosti vrednosti leži torej v cenovni obliki sami. To ni pomanjkljivost te oblike, temveč jo obratno napravi za adekvatno obliko takega produkcijskega načina, v katerem se lahko pravilo uveljavlja samo kot slepo delujoči zakon povprečja brezpravilnosti.« Böhm-Bawerkov »ugovor « tako izkazuje nerazumevanje enega najpreprostejših delov teorije vrednosti. 
zakona vrednosti, češ da visokokvalificiranega nematerialnega dela ni mogoče disciplinirati tako kakor klasično fordistično delo. A Negri pozablja, da kapital ne disciplinira konkretnega dela $\mathrm{v}$ njegovih raznoterih oblikah, temveč $\mathrm{z}$ realno abstrakcijo, ki poteka neodvisno od naše zavesti, ${ }^{7}$ disciplinira abstraktno, homogeno delo, ki ostane brez sleherne konkretne pojavnosti. To je značilen postmarksistični postopek, ki ohrani nekatere marksovske termine, obenem pa domala zanemari teoretsko osnovo Marxove kritike politične ekonomije, tj. zakon vrednosti, tendenčno padanje profitne mere, dvojni značaj dela, vrednostno formo itn. ${ }^{8}$ Postmarksisti bi radi sedeli na dveh stolih hkrati, radi bi obdržali Marxa kot formo in zavrgli Marxa kot substanco. A Marx kot forma je nujni izraz Marxa kot substance, njegovi termini so imena njegovih teoretskih konceptov, tako da jih ne moremo uporabljati metaforično, ne da bi zapadli predteoretski, ideološki praksi.

Simptomatično je, da postmarksizem abstrahira od zgodovinsko specifičnih, nujno spremenljivih produkcijskih odnosov, prek katerih se vzpostavljajo različne forme (re)produkcije celotnega družbenega življenja, in da postulira novo (liberalno) polje boja, politično polje konstituiranja ter kontestacije identitet in diskurzov, ki naj bi bilo (vsaj kot forma) transhistorično in inkluzivno (univerzalni emancipatorni boj ne obstaja, vsaka politična praksa je legitimna, če le ne ogrozi ozko definiranega liberalnega ideala svobode). Postmarksizem omogoča radikalno prakso, ne da bi se ta dejansko spoprijela s silami oblasti, ki določajo okoliščine (re)produkcije družbenega življenja in s tem razvoja vsakega posameznika. Takšne postmoderne politične prakse sicer nemara problematizirajo kakšno »oblastno razmerje«, ne zadenejo pa tistega, ki pogojuje vsa druga. ${ }^{9}$ In nemara lahko postmarksisti zavzamejo celo antikapitalistično držo, a, rečeno z Dunajevsko, njihova antikapitalističnost ni posledica njihovih teorij, ampak je naključen osebnostni vzgib.

\section{Sklep}

Loren Goldner $(2011,13)$ je ontološko in epistemološko podlago postmodernih ved pomenljivo označil za "nočne misli kapitala $\mathrm{v}$ letih, ko je pospešeno mutiral

7 »Ljudje torej svojih delovnih produktov ne postavljajo v medsebojne odnose kot vrednosti zato, ker jim te stvari veljajo kot zgolj stvarni ovoji enakovrstno človeškega dela. Obratno. Ko svoje raznovrstne produkte drugega $\mathrm{z}$ drugim $\mathrm{v}$ menjavi enačijo kot vrednosti, enačijo svoja raznovrstna dela drugo z drugim kot človeško delo. Tega ne vedo, toda to počno« (Marx 1986, 74).

8 Bizarna razdvojenost med hkratno afirmacijo in demantiranjem Marxa doseže vrhunec, ko Negri (2008, 21-22) trdi, da zakon vrednosti - esencialni element Marxove teorije vrednosti - danes sploh ne velja več.

9 Ne zato, ker naj bi »ekonomija« določala »ideologijo in politiko«, ampak zato, ker kapitalistična forma produkcijskih odnosov (tj. vrednostna forma, materializacija oziroma kristalizacija odnosov med ljudmi) določa formo (meje) možnega družbenega življenja. 
v svoje fiktivne forme, na videz ločene od vsakega razmerja s produkcijo ali reprodukcijo«. Skrajna relativizacija in predvsem subjektivizacija, ki preveva modne družbene vede, ni zgolj nevtralno prilagajanje znanstvenemu napredku v polju kvantne mehanike (kot bi rekel Lyotard), ki v nasprotju z dolgočasnimi ideologi moderne dokazuje, da niti nedružbene, naravne realnosti ne moremo zgrabiti s totalizirajočimi, objektivističnimi teorijami, saj je sama življenjska bit objektivno subjektivna. Relativizacija se je $\mathrm{v}$ družbenih vedah začela veliko pred odkritji kvantne mehanike - celo pred samim odkritjem kvantne mehanike kot znanosti -, v sedemdesetih letih 19. stoletja, ko so buržoazni apologeti nasproti Marxovi teoriji vrednosti postavili svoje koncepcije.

Marginalistična teorija vrednosti (kot so jo po Heinrichu Gossnu povzeli Karl Menger, Léon Walras in Stanley Jevons), ki v središče postavi individua in njegove subjektivne preference (med katerimi naj ne bi bila nobena pravilnejša kakor ostale) ter potrošnjo oziroma sfero menjave, kjer, rečeno z Marxom, veljajo liberalni ideali »svobode, enakosti, lastnine in Benthama«, je popolno nasprotje Marxove »objektivne« teorije vrednosti, ki začne s temačno sfero produkcije, kjer tržne zakonitosti ekvivalentne menjave in enakopravnosti ekonomskih akterjev odpadejo. Klasični ekonomisti so z delovno teorijo vrednosti trčili ob štrleče skalovje implikacije, da delo ustvarja vrednost in da je posplošena blagovna menjava inherentno nepravična. Vulgarni ekonomisti so s teorijo "produkcijskih faktorjev", ki postulira neantagonističnost različnih razredov (s produkcijo in menjavo naj bi vsi vzajemno maksimirali svoje koristi), poskusili rešiti to protislovje, a brez uspeha. Marginalizmu je s totalnim abstrahiranjem od vsega, kar je podobno družbenemu življenju in kapitalizmu, uspelo opraviti epohalno nalogo rigorozne, četudi povsem formalistične in zato neaplikabilne apologije obstoječega sistema izkoriščanja. Cena tega uspeha pa je, kot vemo, večno proučevanje imaginarnih scenarijev, v katerih protočlovek Robinzon maksimira svoje subjektivne koristi na osamljenem otoku, nekje nad kontinuumom prostor-čas. Tako je v 19. stoletju umrla ekonomija.

Radikalizem srednjega razreda (Goldner), s katerim se ponaša postmarksizem, je povsem spravljiv z institucionalnimi (in ideološkimi) koordinatami liberalnega kapitalizma in njegovega institucionaliziranega raziskovalno-izobraževalnega aparata. Identitetne politike, ki jih slavi ta aparat, ne subvertirajo kapitalističnih produkcijskih odnosov, ampak jih, obratno, afirmirajo, četudi nehote. Od tod njihovo zanemarjanje radikalnih marksističnih implikacij, natančneje, implikacij Marxove teorije vrednosti. Pri tem ne gre za to, da je Marx za institucionalizirani študij ideologije irelevanten, ampak za to, da njegova kritika politične ekonomije nepovratno demistificira liberalno demokracijo; navsezadnje je bila prav kriza klasične političnoekonomske apologije, 
ki sta jo sredi 19. stoletja implicirali socialistična interpretacija Ricardove delovne teorije vrednosti in predvsem Marxova teorija vrednosti, povod za nastanek omenjene ekonomske paradigme, ki na videz dokončno pokaže, da izkoriščanje ni imanentno kapitalizmu.

Če Marxovi misli slečemo njeno radikalno prevleko, ki je pravzaprav vse, kar jo sestavlja, in na njeno mesto postavimo nekaj, kar ji je podobno, a nima $\mathrm{z}$ njo ničesar skupnega, dobimo marksovsko ali marksistično zvenečo »teorijo«, ki je $\mathrm{v}$ resnici predteoretska apologija. Le tako lahko institucionaliziramo marksizem $\mathrm{v}$ dobi poznega kapitalizma, ki se krčevito rešuje pred pogubnim odvijanjem njegovih lastnih protislovij. V polju ekonomije je to presenetljivo dobro uspelo psihopatološki (Freeman, 1996) neoklasično-marksistični sintezi, ki je teorijo vrednosti oropala ne le substance, temveč tudi implikacij. V polju teorije politike in ideologije pa je to uspelo postmarksizmu, ki je pogodbo $s$ hudičem plačal $\mathrm{z}$ denunciacijo Marxa oziroma $\mathrm{s}$ prevzemom buržoaznega Marxa, ki so ga kakor Frankensteinovo pošast v akademskih laboratorijih sestavili neoklasični doktorji okultnega. Kupčija je bila pogubna. Tako z 20. stoletjem umira projekt radikalne emancipacije.

\section{Literatura}

Bowman, P., Cultural Studies versus Post-Marxism, Edinburgh 2007.

Carchedi, G., Behind the Crisis, Leiden 2011.

Cohen, J., Class and Civil Society, Amherst, MA 1987.

Freeman, A., The Psychopathology of Walrasian Marxism, v: Marx and NonEquilibrium Economics (ur. Freeman, A., Carchedi, G.), Aldershot 1996, str. $1-29$.

Goldner, L., Vanguard of Retrogression, New York 2011.

Katz, A., Postmodern Cultural Studies: A Critique, The Alternative Orange 5, št. 1, 1995/1996, str. 56-70.

Kliman, A., Reclaiming Marx’s »Capital«, Plymouth 2007.

Laclau, E., Politics and Ideology in Marxist Theory, London 1977.

Laclau, E., Why Constructing a People Is the Main Task of Radical Politics, Critical Inquiry 4, 2006, str. 646-680.

Marx, K., Zur Kritik der Politischen Ökonomie. Vorwort, v: Marx, K., Engels, F., Werke. Band 13, Berlin 1971, str. 3-11.

Marx, K., Osemnajsti brumaire Ludvika Bonaparta, v: Marx, K., Engels, F., Izbrana dela III, Ljubljana 1979a, str. 445-574. 
Marx, K., Prispevek h kritiki politične ekonomije. Predgovor, v: Marx, K., Engels, F., Izbrana dela IV, Ljubljana 1979b, str. 101-109.

Marx, K., Kapital, Ljubljana 1986.

Negri, A., The Porcelain Workshop, New York 2008.

Stillman, P. G., The Myth of Marx's Economic Determinism, Marx Myths and Legends, 2005, http://www.marxmyths.org/peter-stillman/article.htm [25. 2. 2013]. 
Tibor Rutar

\section{Post-Marxism's Marx}

Keywords: Post-Marxism, determinism, the critique of political economy, neoclassical economics

In the late 1970s, an entirely new field of social studies, one positing a radically new ontology and epistemology, had emerged. This new field, which included postMarxism, rejected the modernist meta-narratives. This framework included the attempt to integrate Marxism as one of the loftiest meta-narratives into this new relativist paradigm. This task is particularly difficult as it requires that Marxism be both integrated and superseded. I argue that this has taken its toll on the post-Marxist understanding of Marxism itself.

The purpose of my article is twofold. On the one hand, I situate post-Marxism within the crisis of capitalist economies that has been unfolding ever since the early 1970s. On the other hand, and more importantly, I investigate the post-Marxist conception of Marx. I claim that the Marx of post-Marxists isnot the nineteenthcentury humanist thinker who posed a critical and, indeed, irrefutable challenge to the existing social order.

My purpose here is not a thorough critique of the post-Marxist critiques of Marxist thinkers; I am aware of the many differences between the theorists of the heterogeneous field that is post-Marxism, and of the wealth of literature that cannot be addressed here. Rather, I am concerned with a critique of a vulgarised, straw-man Marx that has been construed in the minds of neoclassical economists and the like. I try to demonstrate that there are many similarities (both explicit and implicit) between the new, apologetic economics and the new, postmodern Marxism. 